\title{
CONTINUOUS USE INTENTION OF MOBILE PAYMENT - COMPARISON OF ALIPAY AND WECHAT PAY
}

\author{
Fa-Cheng Tan, Hyesun Hwang, Hyewon Lim, Joo-Hyun Park and Jihyung Hong \\ Sungkyunkwan University, South Korea \\ 25-2, Seonggyungwan-ro, Jongno-gu, Seoul, Republic of Korea
}

\begin{abstract}
This study investigates consumers' continuous use intention of mobile payment services, Alipay and WeChat Pay. Alipay is based on a platform for financial services from its inception, while WeChat Pay is based on a social media platform with the financial service. The result shows that trust and facilitating conditions affect the intention of continuous use of Alipay, and perceived ease of use and social influence affect the continuous use of WeChat Pay. The result indicates the differences in the factors that constitute consumers' acceptance and continuous use intention of mobile payment services based on different platforms.
\end{abstract}

\section{KEYWORDS}

Mobile Payment Services, Continuous Use Intention, UTAUT2, Alipay, WeChat Pay

\section{INTRODUCTION}

This study investigates the continuous use intention of mobile payment services in relation to China's mobile payment market leaders, Alipay and WeChat Pay. China's mobile payment market is the world's largest market. The payment market developed directly from cash to mobile payments without going through a credit cards phase, as the credit card market stopped growing at an early stage (Kim et al., 2015).

The biggest difference between the two platforms is that Alipay was introduced to the market as a platform for financial services from its inception, while WeChat Pay was launched as a social media platform, with the financial service added later (All China Tech, 2017). The characteristics of the two platforms result in differences in the factors that constitute consumers' acceptance and continuous use intention of mobile payment services. We examine the acceptance factors for Alipay and WeChat Pay services and the continuous use intention of both mobile payment services. This study aimed to identify consumer needs and utilize the Fin-Tech industry as baseline data for developing consumer-oriented directions.

\section{METHOD}

Based on the Technical Acceptance Model (TAM), Venkatesh et al. (2003) proposed the Unified Theory of Acceptance and Use of Technology (UTAUT) by extending the model with external variables. This theory includes four dimensions that affect consumers' technology acceptance including performance expectancy, effort expectancy, social influence, and facilitating condition. Venkatesh, Thong, and Xu (2012) suggested the UTAUT2 model as an extension of the existing model by adding entertainment, price value, and habit as personal elements that could affect user acceptance.

Based on the Unified Theory of Acceptance and Use of Technology 2 (UTAUT2), consumers' continuous use intention was analyzed. According to prior research, trust and perceived risks were included in the research model. We investigate a sample of 378 Chinese consumers in the 20-40 years group living in Shanghai who were using both Alipay and WeChat Pay. A hierarchical regression was performed using SPSS 21.0 to analyze consumers' continuous use intention of the two platforms. 


\section{RESULT}

First, based on the demographic characteristics of the consumers, comparing acceptance factors for mobile payment services shows a difference in awareness of perceived risk for both Alipay and WeChat Pay, which depend on a consumer's income level and occupation. On the other hand, in the case of Alipay, the perception level of social influence is correlated to consumers' income levels.

Second, there is no significant difference in perceived ease of use between the two platforms. In addition, consumers' evaluations of Alipay are more positive than those of WeChat Pay for the following six factors: perceived usefulness, trust, perceived risk, social influence, facilitating conditions, and hedonic motivation.

Finally, to investigate consumers' continuous use intention of Alipay and WeChat Pay, we conducted regression analyses. Hedonic motivation has the greatest influence on the continuous use intention of Alipay, followed by perceived usefulness, facilitating conditions, and trust. By contrast, in the case of WeChat Pay, social influence is the most important influential factor for continuous use intention, followed by hedonic motivation, perceived usefulness, and perceived ease of use. Perceived usefulness and hedonic motivation of both Alipay and WeChat Pay have a positive effect on continuous use intention. Trust and facilitating conditions affect the intention of continuous use of Alipay, and perceived ease of use and social influence affect the continuous use of WeChat Pay. This difference seems to result from the differences in the core characteristics of the two platforms.

Table 1. Regression analysis of continuous use intention (Alipay \& WeChat Pay)

\begin{tabular}{|c|c|c|c|c|c|c|c|c|}
\hline & \multirow{2}{*}{\multicolumn{2}{|c|}{ Variables }} & \multicolumn{3}{|c|}{ Alipay } & \multicolumn{3}{|c|}{ WeChat Pay } \\
\hline & & & B & B & $\mathrm{t}$ & B & B & $\mathrm{t}$ \\
\hline Demographic & \multicolumn{2}{|c|}{ Gender $($ male $=1)$} & .009 & .004 & .097 & -.032 & -.013 & -.324 \\
\hline \multirow[t]{4}{*}{ characteristics } & \multicolumn{2}{|l|}{ Age } & -.003 & -.022 & -.462 & .000 & .001 & .024 \\
\hline & \multicolumn{2}{|c|}{ Education (university or more $=1$ ) } & .135 & .059 & 1.194 & .065 & .025 & .542 \\
\hline & Income level & Middle income level & .008 & .004 & .053 & -.206 & -.084 & -1.265 \\
\hline & & High income level & -.015 & -.007 & -.089 & -.405 & -.170 & $-2.331 *$ \\
\hline \multirow[t]{4}{*}{ System factor } & Perceived usef & & .149 & .158 & $3.312 * *$ & .114 & .111 & $2.542 *$ \\
\hline & Perceived ease & use & .009 & .009 & .195 & .100 & .094 & $2.010 *$ \\
\hline & Perceived risk & & .007 & .011 & .227 & -.031 & -.042 & -.920 \\
\hline & Trust & & .111 & .120 & $2.257^{*}$ & .007 & .007 & .139 \\
\hline \multirow[t]{2}{*}{ External factor } & Social influen & & .060 & .075 & 1.461 & .192 & .204 & $4.482 * * *$ \\
\hline & Facilitating co & ions & .138 & .154 & $2.975^{* *}$ & .094 & .096 & 1.937 \\
\hline \multirow[t]{2}{*}{ Internal factor } & Hedonic moti & & .161 & .184 & $3.438 * *$ & .187 & .190 & $3.536 * * *$ \\
\hline & Satisfaction & & .145 & .151 & $2.799 * *$ & .245 & .233 & $4.379 * * *$ \\
\hline Constant & & & \multicolumn{3}{|c|}{1.413} & \multicolumn{3}{|c|}{.509} \\
\hline $\mathrm{R}^{2}$ & & & \multicolumn{3}{|c|}{0.306} & \multicolumn{3}{|c|}{0.408} \\
\hline Adjusted $\mathrm{R}^{2}$ & & & \multicolumn{3}{|c|}{0.281} & \multicolumn{3}{|c|}{0.387} \\
\hline F & & & \multicolumn{3}{|c|}{$12.172 * * *$} & \multicolumn{3}{|c|}{$19.032 * * *$} \\
\hline Durbin-Watson & & & \multicolumn{3}{|c|}{2.164} & \multicolumn{3}{|c|}{1.914} \\
\hline
\end{tabular}

$* \mathrm{p}<.05, * * \mathrm{p}<.01, * * * \mathrm{p}<.001$ 


\section{CONCLUSION}

A comparison between the two platforms confirms that consumers identify commonalities and differences in acceptance factors regarding characteristics of mobile payment service platforms. The continuous development of the mobile payment market has necessitated further research on various platforms of mobile payment services.

\section{REFERENCES}

Alipay vs WeChat Pay - who is winning the battle? (2017, February 28), ASEAN Today. Retrieved from https://www.aseantoday.com/2017/02/alipay-vs-wechat-pay-who-is-winning-the-battle

Kim, B. Y. et al, 2015. Will there be another momentum play? Fin-tech. Weekly Report, NH Investment Securities. Korea Venkatesh, V. et al, 2003. User Acceptance of Information Technology: Toward a Unified View. MIS Quarterly, Vol. 27, No. 3, pp. 425-478.

Venkatesh, V. et al, 2012. Consumer Acceptance and Use of Information Technology: Extending the Unified Theory of Acceptance and Use of Technology. MIS Quarterly, Vol. 36, No. 1, pp. 157-178. 